\title{
PREVALENCE OF GESTATIONAL DIABETES MELLITUS (GDM) AMONG WOMEN ATTENDING ANTENATAL CLINIC OF A TEACHING HOSPITAL IN CENTRAL KERALA
}

\author{
Sholy K. Vareed ${ }^{1}$, Aravindakshan V. N², Swati Patki ${ }^{3}$, Gopalakrishnan Padmanabhan ${ }^{4}$, Ann Mary Thomas ${ }^{5}$, \\ Harsha Chollankil Hariharan', Neethu Mary ${ }^{7}$, Raju Antony ${ }^{8}$
}

\begin{abstract}
${ }^{1}$ Assistant Professor, Department of Radio-diagnosis, Sree Narayana Institute of Medical Sciences, Ernakulam, Kerala. ${ }_{2}^{2}$ Assistant Professor, Department of General Surgery, Sree Narayana Institute of Medical Sciences, Ernakulam, Kerala. 3Professor, Department of Community Medicine, Sree Narayana Institute of Medical Sciences, Ernakulam, Kerala. ${ }^{4}$ Associate Professor cum Epidemiologist, Dept. of Community Medicine, Sree Narayana Institute of Medical Sciences, Ernakulam. ${ }_{5}^{5}$ Assistant Professor, Department of Community Medicine, Sree Narayana Institute of Medical Sciences, Ernakulam, Kerala. ${ }^{6}$ Assistant Professor in Biostatistics, Dept. of Community Medicine, Sree Narayana Institute of Medical Sciences, Ernakulam, Kerala. ${ }^{7}$ Tutor, Department of Community Medicine, Sree Narayana Institute of Medical Sciences, Ernakulam, Kerala. ${ }^{8}$ Professor, Department of Community Medicine, Sree Narayana Institute of Medical Sciences, Ernakulam, Kerala.
\end{abstract}

\section{ABSTRACT}

\section{BACKGROUND}

Gestational Diabetes Mellitus (GDM) is a metabolic disorder defined as glucose intolerance with the onset or first recognition during pregnancy. Prevalence of gestational diabetes mellitus is reported to be between $2 \%-8 \%$, distributed across all continents and cultures. In South India, the prevalence of GDM increased from 1\% in 1998 to 16.55\% in 2004. In a recent community based study conducted by Seshiah et al in South India, GDM was reported among 17.5\% of women in urban, 13.8\% in semi urban, 9.9\% in rural areas based on two-hour 75 gm post glucose value greater than or equal to $140 \mathrm{mg} / \mathrm{dL}$. Women with GDM are at increased risk for adverse obstetric and perinatal outcomes. Diabetes complicates between 1 and $20 \%$ of all pregnancies worldwide, which include pre-gestational diabetes and GDM. Hence, Research regarding GDM is essential to understand the burden of the problem and its impact.

The objectives of this study is to estimate the prevalence of GDM among attendees of an Antenatal Clinic at a Teaching Hospital in Ernakulam district to assess factors associated with GDM and to determine the maternal and neonatal complications associated with GDM.

\section{MATERIALS AND METHODS}

A retrospective hospital-based study was done utilising records from first quarter of 2016, containing the data of 135 pregnant women who had attended the Antenatal Clinic of a Private Medical College in Ernakulam district. Data related to maternal complications in the natal or post-natal period and neonatal outcome/complications was also obtained from hospital records.

\section{RESULTS}

A total of 135 pregnant women were registered and screened for GDM as per records. GDM was detected in 16 antenatal women. Majority of GDM cases, 10 (62.5\%) were in the age group of 25 - 31 years and 31.25\% of GDM cases were primi-gravidae. Of the GDM cases, 7 had maternal complications. Among the antenatal women with GDM, 11 (68.75\%) underwent LSCS; there was only 1 (6.25\%) preterm delivery, 1 neonate had low birth weight and 6 (37.5\%) had neonatal complications.

\section{CONCLUSION}

Among the 135 women, 16 (11.9\%) had GDM. Prevalence of GDM was more in the age group of 25 - 31 yrs. and among multigravidae. Majority underwent LSCS.

\section{KEYWORDS}

Prevalence, GDM, Maternal Complications, Neonatal Complication.

HOW TO CITE THIS ARTICLE: Vareed SK, Aravindakshan VN, Patki S, et al. Prevalence of gestational diabetes mellitus (GDM) among women attending antenatal clinic of a teaching hospital in Central Kerala. J. Evolution Med. Dent. Sci. 2017;6(7):524-526, DOI: $10.14260 /$ Jemds/2017/111

\section{BACKGROUND}

GDM is a metabolic disorder defined as glucose intolerance with the onset or first recognition during pregnancy with or without remission after the end of pregnancy.[1]

Financial or Other, Competing Interest: None.

Submission 03-01-2017, Peer Review 15-01-2017,

Acceptance 17-01-2017, Published 23-01-2017.

Corresponding Author:

Dr. Swati Patki,

Professor, Department of Community Medicine,

SNIMS, Ernakulam, Kerala.

E-mail:drpatkism@yahoo.com

DOI: $10.14260 /$ jemds $/ 2017 / 111$

\section{(c) (i) $\$$}

According to WHO guidelines, diagnosis of diabetes mellitus is made when plasma glucose concentrations exceed $144 \mathrm{mg} / \mathrm{dL}$ in the fasting state and/or the 2-hour oral glucose tolerance test value is greater than or equal to $200 \mathrm{mg} / \mathrm{dL}$ and worldwide prevalence of gestational diabetes mellitus is reported between $2 \%$ - $8 \%$, distributed across continents and cultures.[2] The prevalence of GDM is high in the Indian population as compared to other population of South East Asia; in South India, the prevalence of GDM is increased from $1 \%$ in 1998 to $16.55 \%$ in 2004.[3] Women with GDM are at increased risk for adverse obstetric and perinatal outcomes. Diabetes complicates between 1 and $20 \%$ of all pregnancies worldwide, which include pre-gestational diabetes and GDM. 
In a recent community based study conducted by Seshiah et al in South India, GDM was detected among $17.5 \%$ of women in urban, $13.8 \%$ in semi urban, $9.9 \%$ in rural areas based on two-hour $75 \mathrm{gm}$ post glucose value greater than or equal to $140 \mathrm{mg} / \mathrm{dL} .[4]$ Hence, Research regarding GDM is essential to understand the burden of the problem and its impact.

This study was undertaken to determine the prevalence of GDM among women attending an Antenatal Clinic at a Teaching Hospital in Ernakulam, Kerala, to assess factors associated with GDM and to determine the maternal and neonatal complications associated with GDM.

\section{MATERIALS AND METHODS}

Study Design - Retrospective hospital based study.

Study Setting - A teaching hospital in Kerala.

Sample Size - Total of 135 pregnant women who had attended the Antenatal Clinic of a teaching hospital during the period of 3 months (January to March, 2016).

Approval was sought from Institutional Research and Ethics Committee. Data was obtained from hospital records. Diagnosis of GDM was made according to WHO guidelines. All the pregnant women had undergone oral glucose tolerance test at $24-28$ weeks of gestation. Blood samples obtained after 8 hours of overnight fast and 1 and 2 hours after $75 \mathrm{~g}$ oral glucose load. The diagnosis of GDM was made when any of the following plasma glucose values exceeded: fasting $\geq 92$ $\mathrm{mg} / \mathrm{dL}, 1$ hour $\geq 180 \mathrm{mg} / \mathrm{dL}$ and 2 hours $\geq 153 \mathrm{mg} / \mathrm{dL}$. Pregnant women who were diagnosed with GDM received individualised diet and/or insulin treatment and also underwent periodical clinical and biochemical evaluations every 2 weeks or more frequently when appropriate. Data related to maternal complications and neonatal outcome/complications was also obtained from hospital records.

The data collected was entered and analysed using MS Excel and Epi Info 7. Frequency and percentages were calculated and chi square test used to determine the associated factors.

\section{RESULTS}

A total of 135 pregnant women were registered and screened for GDM as per records. Of these 135 cases, GDM was detected in 16 antenatal women.

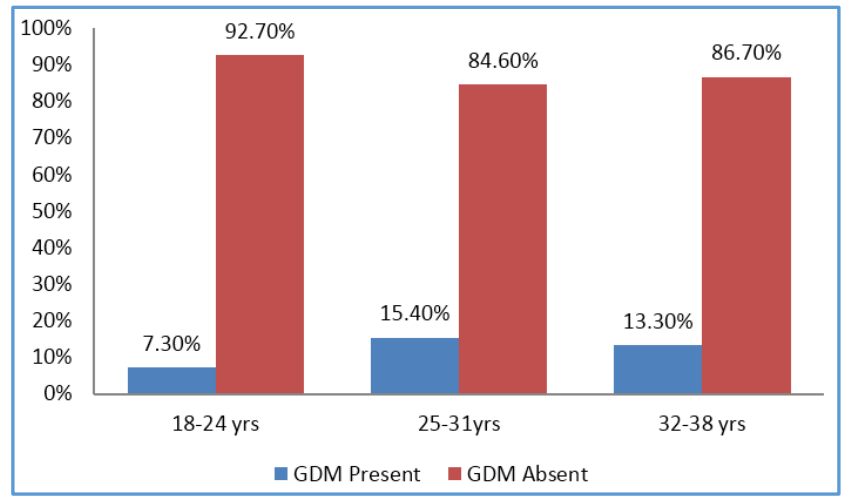

Figure 1. Distribution of Antenatal Women according to Age Group

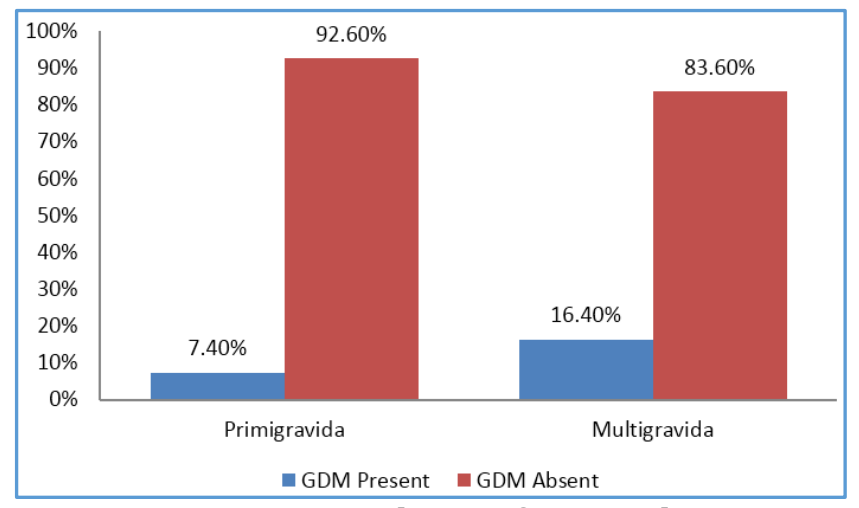

Figure 2. Distribution of Antenatal Women according to Parity

\begin{tabular}{|c|c|c|c|c|c|}
\hline \multirow{2}{*}{ GDM } & $\begin{array}{c}\text { Maternal } \\
\text { Complications }\end{array}$ & \multirow{2}{*}{ Total } & $\begin{array}{c}\text { Chi } \\
\text { Square } \\
\text { Value }\end{array}$ & $\begin{array}{c}\text { P } \\
\text { value }\end{array}$ \\
\cline { 2 - 4 } & Yes & No & & \\
Present & $7(43.8 \%)$ & $9(56.2 \%)$ & $16(100 \%)$ & & \multirow{2}{*}{0.477} \\
\hline Absent & $63(52.9 \%)$ & $56(47.1 \%)$ & $119(100 \%)$ & \\
\hline Total & $\mathbf{7 0}$ & $\mathbf{6 5}$ & $\mathbf{1 3 5}$ & & \\
\hline \multicolumn{6}{|c|}{$\begin{array}{c}\text { Table 1. Distribution of Antenatal Women } \\
\text { according to Maternal Complications }\end{array}$} \\
\hline
\end{tabular}

Among the antenatal women, maternal complications were seen in 7 (43.8\%) of those with GDM and $63(52.9 \%)$ of those without GDM. Statistically, there was no association between GDM and maternal complications.

\begin{tabular}{|c|c|c|c|c|c|}
\hline \multirow{2}{*}{ GDM } & \multicolumn{4}{|c|}{ Type of Delivery } & \multirow{2}{*}{ Total } \\
\cline { 2 - 5 } & Normal & LSCS & $\begin{array}{l}\text { Vacuum } \\
\text { Delivery }\end{array}$ & IUD & \\
\hline Present & $\begin{array}{c}5 \\
(31.25 \%)\end{array}$ & $\begin{array}{c}11 \\
(68.75 \%)\end{array}$ & 0 & 0 & 16 \\
\hline Absent & $\begin{array}{c}52 \\
(43.69 \%)\end{array}$ & $\begin{array}{c}63 \\
(52.94 \%)\end{array}$ & $\begin{array}{c}2 \\
(1.68 \%)\end{array}$ & $\begin{array}{c}2 \\
(1.68 \%)\end{array}$ & 119 \\
\hline Total & $\mathbf{5 7}$ & $\mathbf{7 4}$ & $\mathbf{2}$ & $\mathbf{2}$ & $\mathbf{1 3 5}$ \\
\hline \multicolumn{5}{|c|}{ Table 2. Distribution of antenatal } \\
Women according to Type of Delivery \\
\hline
\end{tabular}

IUD - Intrauterine Death.

Of 16 cases of GDM 5 (31.25\%) cases had normal delivery, while 11 (68.75\%) underwent LSCS.

\begin{tabular}{|c|c|c|c|c|}
\hline Mother's & \multicolumn{4}{|c|}{ Neonatal Outcome } \\
$\begin{array}{c}\text { Gestational } \\
\text { Diabetic Status }\end{array}$ & Preterm & Full term & IUD $^{*}$ & Total \\
\hline GDM & 1 & 15 & 0 & \\
\hline No GDM & 1 & 116 & 2 & \\
\hline Table 3. Distribution of Antenatal Women \\
according to Neonatal Outcome \\
\hline
\end{tabular}

*IUD - Intrauterine Death.

\begin{tabular}{|c|c|c|c|}
\hline & \multicolumn{2}{|c|}{ Birth Weight of Baby (gm) } & \\
\hline & $<2500$ & $\geq 2500$ & Total \\
\hline GDM & $1(6.2 \%)$ & $15(93.8 \%)$ & $16(100 \%)$ \\
\hline No GDM & $24(20.2 \%)$ & $95(79.8 \%)$ & $119(100 \%)$ \\
\hline Total & 25 & 110 & 135 \\
\hline
\end{tabular}

Of the neonates born to mothers with GDM, 15 (93.75\%) were full term and $1(6.25 \%)$ was preterm and only 1 had low birth weight. 


\begin{tabular}{|c|c|c|c|c|c|}
\hline \multirow{2}{*}{ GDM } & \multicolumn{2}{|c|}{$\begin{array}{c}\text { Neonatal } \\
\text { Complications }\end{array}$} & \multirow{2}{*}{ Total } & $\begin{array}{c}\text { Chi Square } \\
\text { Value }\end{array}$ & $\begin{array}{c}\text { P } \\
\text { value }\end{array}$ \\
\cline { 2 - 4 } Yes & No & & \\
Present & $\begin{array}{c}6 \\
(37.5 \%)\end{array}$ & $\begin{array}{c}10 \\
(62.5 \%)\end{array}$ & $\begin{array}{c}16 \\
(100 \%)\end{array}$ & & \multirow{2}{*}{0.001} \\
\cline { 1 - 3 } Absent & $\begin{array}{c}45 \\
(37.8 \%)\end{array}$ & $\begin{array}{c}74 \\
(62.2 \%)\end{array}$ & $\begin{array}{c}119 \\
(100 \%)\end{array}$ & & \\
\hline Total & $\mathbf{5 1}$ & $\mathbf{8 4}$ & $\mathbf{1 3 5}$ & & \\
\hline \multicolumn{6}{|c|}{ Table 5. Distribution of Antenatal Women } \\
according to Neonatal Complications \\
\hline
\end{tabular}

Neonatal complications were seen in 6 (37.5\%) neonates born to mothers with GDM. There was no significant association between GDM and neonatal complications.

\section{DISCUSSION}

In our study the prevalence of GDM was found to be $11.9 \%$, whereas a study conducted by Seshiah et al[5] showed a prevalence of $13.9 \%$.

Our study found that the prevalence of GDM is more in women of age group of 25 - 31 years (15.4\%); this is similar to a community based study in Tami Nadu by Seshiah et al.[6]

Our study showed that the prevalence of GDM is more, 11 (16.4\%) among multigravidae than in primi-gravidae 5 (7.4\%), similar to that of a study by Crypryk $\mathrm{K}$ et al according to which the prevalence of GDM in multiparous women was $16 \% .{ }^{[7]}$

Of 16 cases of GDM, 7 (43.8\%) had maternal complications. Incidence of maternal complications was higher in non-GDM women 63 (52.9\%). In a study conducted by Zargar A $\mathrm{H}$ et al among Kashmiri women, it was seen that maternal complications were more prevalent in mothers with GDM.[8] Our study found that prevalence of low birth weight was $1(6.2 \%)$ in GDM women and prevalence of low birth weight baby in non-diabetic women was 24 (20.2\%). In a study conducted by Shefali AK et al, among Asian Indian mothers (CURES - 35), prevalence of low birth weight was $14.3 \%$ in neonates of non-diabetic mothers, $12.3 \%$ in pregestational diabetes and 8.2\% in GDM.[9]

\section{CONCLUSION}

Among the 135 women, 16 (11.9\%) had GDM. Prevalence of GDM was more in the age group of 25 - 31 yrs. and among multigravidae. This gives an insight into groups, which require more attention in terms of screening. Out of 16 cases of GDM, majority underwent LSCS. Of the neonates born to these mothers only 1 was preterm, 1 had low birth weight and neonatal complications were seen in 6 of them. The impact of GDM is emphasized by these findings.

Since this is a record based study, the results cannot be extrapolated to the community. It can be achieved with a prospective cohort study with detailed followup for complications and pregnancy outcome.

\section{Recommendations}

Since the prevalence of GDM was found to be $11.9 \%$. It points urgent need for screening all the antenatal women for Gestational Diabetes, especially in a population where overall prevalence of Diabetes is very high. Monitoring blood sugar during every antenatal visit is also essential. Need for screening and assessment even at primary health care level is mandatory, especially for early referrals and prevents maternal and neonatal complications.

\section{Limitations of the Study}

This is a retrospective study with hospital records and the sample studied was very small. Large cohort and longer duration of the study in the future will help in establishing association between the risk factors associated with the study. A prospective study of antenatal cohort would provide more data related to maternal and neonatal risk factors.

\section{Acknowledgement}

We are grateful to Dr. Ambika Bhai, Head of the Department of Obstetrics and Gynaecology; Dr. Tomy Varghese, Medical Superintendent and Medical Record Department for providing essential data for the completion of the Research. We are also thankful to all the antenatal women and their families for consenting to utilise the data for our research.

\section{REFERENCES}

[1] Kalra P, Kachhwaha CP, Singh HV. Prevalence of gestational diabetes mellitus and its outcome in western Rajasthan. Indian Journal Endocrinology Metabolism 2013;17(4):677-680.

[2] Sonali S, Mukhopadhya P, Saha TK, et al. Gestational diabetes: how risky are the mothers of rural Bengal, India. GJMEDPH 2012;1(6):1-3.

[3] Bhat M, Sarma SP, Menon S, et al. Determinants of Gestational Diabetes mellitus: a case control study in a district tertiary care hospital in south India. Indian Journal of Diabetes 2010;30(2):91-6.

[4] Shriraam V, Rani MA, Sathiyasekaran BW, et al. Awareness of gestational diabetes mellitus among antenatal women in primary health centre in south India. Indian Journal Endocrinology Metabolism 2013;17(1):146-8.

[5] Seshiah V, Balaji V, Balaji MS, et al. Pregnancy and diabetes scenario around the world: India. Int J Gynaecol Obstet 2009;104(Suppl 1):S35-8.

[6] Seshiah V, Balaji V, Balaji MS, et al. Prevalence of gestational diabetes mellitus in South India (Tamil Nadu)--a community based study. J Assoc Physicians India 2008;56:329-33.

[7] Cypryk K, Szymczak W, Czupryniak L, et al. Gestational diabetes mellitus - an analysis of risk factors. Endokrynol Pol 2008;59(5):393-7.

[8] Zargar AH, Sheikh MI, Bashir MI, et al. Prevalence of gestational diabetes mellitus in Kashmiri women from the Indian subcontinent. Diabetes Res Clin Pract 2004;66(2):139-45.

[9] Shefali AK, Kavitha M, Deepa R, et al. Pregnancy outcomes in pre-gestational and gestational diabetic women in comparison to non-diabetic women-A prospective study in Asian Indian mothers (CURES-35). J Assoc Physicians India 2006;54:613-8. 